\title{
The Influence of Hydrogen on Vaporization, Mixture Formation and Combustion of Diesel Fuel at an Automotive Diesel Engine
}

\author{
Alexandru Cernat ${ }^{1}$, Constantin Pana ${ }^{1}$, Niculae Negurescu ${ }^{1}$, Gheorghe Lazaroiu ${ }^{2, *}$ and Cristian Nutu ${ }^{1}$ \\ 1 Department of Thermotechnics, Engines, Thermal and Frigorific Equipment, University Politehnica \\ of Bucharest, 060042 București, Romania; cernatalex@yahoo.com (A.C.); constantinpana1@gmail.com (C.P.); \\ niculae_negurescu@yahoo.com (N.N.); nikolaoscristian87@gmail.com (C.N.) \\ 2 Department of Energy Generation and Use, University Politehnica of Bucharest, 060042 București, Romania \\ * Correspondence: glazaroiu@yahoo.com; Tel.: +40-072-280-8709
}

check for updates

Citation: Cernat, A.; Pana, C.;

Negurescu, N.; Lazaroiu, G.; Nutu, C. The Influence of Hydrogen on Vaporization, Mixture Formation and Combustion of Diesel Fuel at an Automotive Diesel Engine. Sustainability 2021, 13, 202. https:// doi.org/10.3390/su13010202

Received: 21 November 2020 Accepted: 19 December 2020 Published: 28 December 2020

Publisher's Note: MDPI stays neutral with regard to jurisdictional claims in published maps and institutional affiliations.

Copyright: () 2020 by the authors. Licensee MDPI, Basel, Switzerland. This article is an open access article distributed under the terms and conditions of the Creative Commons Attribution (CC BY) license (https: / creativecommons.org/ licenses/by/4.0/).

\begin{abstract}
Hydrogen can be a viable alternative fuel for modern diesel engines, offering benefits on efficiency and performance improvement. The paper analyses the results of a thermodynamic model developed by authors in order to study the influence of Hydrogen addition on a process like vaporization, mixture forming, and combustion at the level of diesel fuel droplets. The bi-zonal model is applied for a dual-fueled diesel engine $\mathrm{K} 9 \mathrm{~K}$ type designed by Renault for automotives. For the engine operating regime of $2000 \mathrm{rpm}$ speed and 55\% engine load, the diesel fuel is partially substituted by Hydrogen in energetic percents of $6.76 \%, 13.39 \%$, and $20.97 \%$, the engine power being maintained at the same level comparative to classic fueling. At Hydrogen addition, the diesel fuel jets atomization and diesel fuel droplets vaporization are accelerated, the speed of formation of the mixture being increased. Comparative to classic fueling, the use of Hydrogen leads to diesel droplets combustion intensification, with a shortened autoignition delay, reduction of combustion duration, and increase of flame radius.
\end{abstract}

Keywords: vaporization; mixture; combustion; flame; diesel engine; hydrogen fuel; diesel fuel droplet

\section{Introduction \\ 1.1. Pollutant Emissions of Diesel Engines}

For decades, the use of alternative fuels to fuel internal combustion engines have been promoted in order to reduce the pollutant emissions emitted by automotives. Moreover, in the future, years of 2030-2050, the use of alternative fuels will ensure the reduction of pollutant emissions and greenhouse gases (GHG) of automotive internal combustion engines (ICE)'s [1-3]. During the combustion process, the largest share in the combustion gases is attributed to nitrogen, carbon dioxide, and water, chemical elements that are not toxic. However, a higher emission level of $\mathrm{CO}_{2}$ can amplify the greenhouse effect [4]. The main pollutant substances emitted by the internal combustion engine are $\mathrm{CO}, \mathrm{NO}_{\mathrm{x}}, \mathrm{HC}$, and particles. These substances are toxic and a decrease in their level is necessary. The $\mathrm{CO}$ is a colorless, inodorous, and insipid gas that appears in combustion gases during the incomplete combustion of fuel or as a result of dissociation reaction at high temperatures reached in the combustion chamber.

The $\mathrm{NO}_{x}$ consists of $\mathrm{NO}$ and $\mathrm{NO}_{2}$, the $\mathrm{NO}_{2}$ being four times more toxic compared to $\mathrm{NO}$ and, in special conditions, in combination with $\mathrm{HC}$ can form photochemical smog. The $\mathrm{NO}_{\mathrm{x}}$ formation is influenced by temperature, dosage and available time, a longer residence time of oxygen and combustion gases in high temperature leads to the highest $\mathrm{NO}_{\mathrm{x}}$ emission level. The concentration of $\mathrm{CO}$ is also influenced by $\mathrm{NO}_{\mathrm{x}}$ formation kinetics. Unburned hydrocarbons, HC, represent fuel fractions that were not completely burned. Moreover, unburned-HC's are thermal cracking products. At diesel engines, the HC emission level is related to the incomplete combustion caused by difficulties presented at the formation of the mixture [4]. 
Carbon complexes, tars in the solid and liquid state, which are suspended into exhaust gases, defined as smoke and particles. At diesel engines, the exhaust smoke is composed of soot particles and liquid particles of unburned or partial oxidized fuel. According to the appearance, the following types of smoke are distinguished:

- whitish smoke (or cold smoke) which appears at engine cold start, is composed of liquid fuel particles in suspension. Its specific color appears due to droplet diameter over $0.8 \mu \mathrm{m}$, the wavelength corresponding to blue light, for which droplets appear in white color;

- blue smoke - the engine heats up and the smoke turns blue as a result of the reduction in the diameter of the droplets below $0.8 \mu \mathrm{m}$. The droplets appear colored blue, the smoke being visible at about one meter from the exhaust pipe;

- $\quad$ bluish-grey smoke-occurs when oil enters the combustion chamber because of leak tightness of the piston rings and advanced wear of the valve guides;

- black smoke (or hot smoke) — consists of carbon particles resulted from the incomplete combustion process. In the area with high temperatures, the cracking process occurs and forms carbon complexes, which together with aromatic hydrocarbons and tars, by agglomeration, produce flakes that form hot soot during a coagulation process; the black smoke occurs at high load, at acceleration, or at idle operating regime [4].

The level of all these emissions is correlated with the combustion mode, which must be studied in as much detail as possible. Furthermore, the use of alternative fuels may represent an efficient instrument to decrease the pollutant emissions level $[1,2,5,6]$. In the EU report of future fuels, Vision 2050, the substitution of hydrocarbon fuel types for ICE is specified [1]. According to the report the internal combustion engine will still have, a key role" in transportation, but the $\mathrm{CO}_{2}$ must be reduced by $3 \%$, especially for heavy-duty diesel engines for 2030-2050 [1]. The use of alternative fuels will improve the ICE operation and the ICE will be more efficient, according to Vision 2050. Low carbon fuels can reduce the emissions of internal combustion engines, the engines must be, easily adaptable to future low-emission fuels in the future, low-carbon fuels being recommended [1]. According to the European Union (EU) Report on Alternative Fuels, the use of Hydrogen as a fuel in ICE will have an important role in the years 2030-2050, in a strategy for $\mathrm{CO}_{2}$ reduction and zero-emissions [2]. The use of Hydrogen must be supported and accelerated by the economy according to the report [2]. Another report of UE on alternative fuels presents Hydrogen as the most common fuel stored on vehicles board in pressured tanks [3]. For example, Hydrogen use for ICE fueling leads to a large autonomy comparable with electric vehicles [3].

Among the alternative fuels, Hydrogen can be a viable alternative fuel for ICE [1-10].

\subsection{Hydrogen as Alternative Fuel for Diesel Engines}

The use of Hydrogen as an alternative fuel to replace petroleum-type fuels is very attractive due to the fact that the energetic cycle of Hydrogen is much shorter compared to petroleum fuels [4]. The use of Hydrogen to replace the classic fuel of the diesel engines, as partial or total substitution, may assure the improvement of engine efficiency and pollution. However, it may require resolving different issues in correlation with the physic-chemical properties of this alternative fuel, which are different compared to diesel fuel. Compared to petroleum fuels, Hydrogen has a high diffusion speed when it flows through fuel lines. In order to prevent Hydrogen licking, special materials are required for fueling line design. Furthermore, the increased diffusion speed at commixture with air may lead to a possibility to assure very homogeneous mixtures between air and $\mathrm{H}_{2}$. The combustion of homogeneous mixtures can ensure the reduction of particle and $\mathrm{NO}_{\mathrm{x}}$ emission levels, the in-cylinder zones defined by high temperature or rich dosage being reduced [4].

The $\mathrm{H}_{2}$ autoignition temperature is much higher compared to diesel $\left(570-580{ }^{\circ} \mathrm{C}\right.$ versus $225{ }^{\circ} \mathrm{C}$ for diesel fuel) or compared to other gaseous fuels ( $480-545{ }^{\circ} \mathrm{C}$ for LPG, $540{ }^{\circ} \mathrm{C}$ for $\mathrm{CNG}$ ) [4]. Thus, to assure the ignition of air- $\mathrm{H}_{2}$ mixture the use of diesel fuel pilot injection is required. The combustion speed of Hydrogen is superior to diesel fuel 
(for stoichiometric mixtures $2.4 \mathrm{~m} / \mathrm{s}$ versus $0.3 \mathrm{~m} / \mathrm{s}$ ) [4], and the Hydrogen presence inside the cylinder can increase the combustion speed, the duration of the combustion process being reduced. A shortened combustion duration can be associated with increased values for maximum pressure and maximum pressure increase rate comparative to diesel fueling. The ignition energy has a very low value for $\mathrm{H}_{2}$ comparative to petroleum fuels, $(0.0018 \mathrm{~mJ}$ versus $0.23-0.3 \mathrm{~mJ}$ ) [4], and even at low temperatures Hydrogen can ignite on contact with hot residual gases or on contact with hot surfaces of engine parts such as: inlet manifolds, valves, cylinder walls, piston head, etc. Thus, phenomena of preignition or spontaneous ignition may occur at Hydrogen use. Usually, after preignition in the combustion chamber, the flame returns to the inlet section and an inlet misfire can occur. To avoid these abnormal phenomena during combustion, a special technical solution in engine design and in the $\mathrm{H}_{2}$ fueling system must be applied. For engine design, the technical solutions may imply the modification of valves overlap, cooling of valves, and the use of special piston oil rings. In the inlet system, for stoichiometric conditions, the minimum temperature of ignition is $\sim 400{ }^{\circ} \mathrm{C}$ at 0.005 bar [4], a condition that is not met in the case of internal combustion engines. For a homogeneous mixture of air and $\mathrm{H}_{2}$, during the inlet process, defined by pressures over 0.133 bar and temperatures above $527^{\circ} \mathrm{C}$ [4], the explosion limits are not reached.

The preignition phenomena during the inlet process are related to higher local temperatures in some in-cylinder zones. Thus, the fueling system may require the use of special materials and flame arrestors. Abnormal combustion phenomena can be avoided if the Hydrogen is separated from the air, the Hydrogen being injected in the final section of the inlet system [4]. The wide flammability limits of the air-Hydrogen mixture $(\lambda=0.13-10.12)$ compared to the air-diesel fuel mixture $(\lambda=0.3-1.6)$ [4] can facilitate stable operating conditions at the use of lean mixtures and efficiency increase. Higher low heating value (LHV) of Hydrogen $(119,600 \mathrm{~kJ} / \mathrm{kg})$ versus diesel fuel $(42,500 \mathrm{~kJ} / \mathrm{kg})$ can assure the improvement of the combustion process even if small $\mathrm{H}_{2}$ quantities are used [4]. Hydrogen use as an alternative fuel for ICE's is a research topic studied in actual research activities developed in research institutes, plants, or universities. For example, in an interview for the H2-view site, with a topic related to the decarbonization of the transportation sector, the R\&D department of BMW researches affirm that the EU directive classifying the hydrogen combustion engine as a 'zero-emission' propulsion system in 2019 [8]. According to Koch [9], Hydrogen can be used to fuel the internal combustion engines used for heavy-duty vehicles due to a zero-emission level advantage. Thus, classic engines can be converted for Hydrogen fueling and the EGR and lean-combustion strategy can be applied at Hydrogen use [9].

In a study of fuel use, the Toyota chairman, Takeshi Uchiyamada, affirms that "Hydrogen is the key to a decarbonized future", the Toyota Company being convinced by the benefits of Hydrogen utilization as fuel in the future [10]. Since the European Union started the program "European Clean Hydrogen Alliance" in July 2020, the Hydrogen ICE can be a zero-emission solution for power train systems.

The FEV Company, which develops engine and powertrain durability tests in special cells created in Vehicle and Powertrain Development Centers, focused their new activities on Hydrogen internal combustion engine development [11]. The FEV Company develops research activities to define design, calibration, and testing of Hydrogen-fueled engines, for stationary applications, for personal and commercial vehicles, the larger engines having a power performance of $640 \mathrm{~kW}$. The specialists of FEV define Hydrogen engine as a sustainable technology with high potential in many fields of application, especially for transportation areas where the electric batteries are inefficient for large commercial vehicles or large passenger cars, ships, or trains [11]. FEV researchers have developed new technologies for fueling system, ignition system, crankcase ventilation, exhaust gas after treatment, and engine control for Hydrogen use [11]. The efficiency of a Hydrogen fueled engine is superior to a fuel cell, also taking into consideration the total weight of the vehicle, the efficiency being dependable by load [11]. According to FEV, the Hydrogen supply infrastructure will be ready in 2030 [11]. Korn [12] affirms that the targets in $\mathrm{CO}_{2}$ reductions 
can be assured with modern combustion engines fueled by Hydrogen. If hydrogen is used to fuel the internal combustion engine of a vehicle, then this vehicle is capable of fulfilling the EU norms in terms of "zero-emission vehicle", if the emission level is less than $1 \mathrm{~g}$ $\mathrm{CO}_{2} / \mathrm{kWh}[12]$.

New technologies for Hydrogen injection systems will improve the fuel efficiency compared to classic diesel engines, the interest being especially shown for commercial vehicles [12]. Korn [12] exemplifies that trucks or buses can be equipped with engines fueled by Hydrogen, with an $\mathrm{H}_{2}$ port fuel injection system, with less fuel consumption versus automotives equipped with fuel cells [12]. A less fuel consumption is correlated with the increase of engine efficiency at Hydrogen use and good combustion properties of Hydrogen (higher LHV, combustion speed, etc.).

Szwaja [13] uses Hydrogen to fuel a compression ignition engine (CIE) based on homogeneous charge compression ignition (HCCI) technology. Szwaja studies the Hydrogendiesel co-combustion in a diesel engine [13]. For stoichiometric dosage and $17 \%$ hydrogen, the knock phenomena may occur, being promoted by the use of small quantities of Hydrogen. Small quantities of Hydrogen, up to $5 \%$, were also used to decrease the ignition delay in diesel engine operation and to reduce the pressure increase rate during combustion [13]. These aspects are related to wider flammability limits and a higher combustion speed of Hydrogen. Szwaja [13] uses this method to provide higher reliability of the engine and a smooth engine operation. Karagoz [14] uses Hydrogen as additive fuel for a diesel engine, the diesel fuel being used as an igniter. At full engine load and 750-100 rpm speed domain, Hydrogen percents of 25\% and 50\%, from the total amount of energy introduced per cycle, are used [14]. At the increase of Hydrogen cyclic amount, the peak values of combustion pressure and heat release start to increase [14].

Tutak [15] uses Hydrogen and diesel to fuel a stationary engine, showing the possibility to replace biodiesel with Hydrogen in a percentage up to $38 \%$, as an energetic percent [15]. The use of $\mathrm{H}_{2}$ leads to the decrease of the total combustion duration; Hydrogen fueling assures the decrease of the diffusive phase and the increase of the kinetic phase [15]. At maximum Hydrogen doses, the second peak of the heat release rate characteristic was higher compared to the first peak attributed to premixed combustion [15]. If Hydrogen is used, the in-cylinder mixture ignites sooner compared to classic fuel and the combustion process is shortened [15]. The combustion duration decreases with $13.5^{\circ} \mathrm{CA}$ at 38\% Hydrogen versus biodiesel, the thermal losses being reduced too. Higher LHV and combustion speed of $\mathrm{H}_{2}$ leads to these phenomena. Qin [16] shows that the use of Hydrogen leads to the acceleration of the combustion into a diesel engine, the heat release rate increasing by $3.7 \%$ at the increase of the Hydrogen amount to $20 \%$. During combustion, the maximum pressure increases by $3.7 \%$ at the same amount of Hydrogen [16]. Through Hydrogen use, Qin [16] observes a sooner heat release achievement per cycle, the heat release is increased during the premixed phase and decreased during the diffusive phase. These phenomena are related to a higher combustion speed of Hydrogen, which assures the reduction of the duration of all combustion phases.

Temizer [17] develops theoretical and experimental investigations on a diesel engine at the speed of $2000 \mathrm{rpm}$, for two types of combustion chambers, standard and modified, which are analyzed with a modeling program. At the use of 5 mass percent of Hydrogen beside diesel fuel, the pressure and temperature during combustion start to increase compared to diesel fueling [17]. At the increase of Hydrogen quantity, Temizer [17] observes the increase of the heat release and of the flame velocity during flame propagation. Comparative to diesel fuel, Hydrogen has a higher lower heating value, higher combustion speed, and large flammability limits, properties that influence the obtained results.

Hoang [18] presents Hydrogen as a viable alternative fuel, which can replace the classic fuels, even in diesel engines. Small Hydrogen quantities can accelerate the combustion process. The combustion speed is increased, due to rapid diffusion and combustion of Hydrogen, the complete combustion of the air-fuel mixture being ensured [18]. Hoang [18] uses Hydrogen to fuel a stationary diesel engine connected with an electric generator, the 
improvement of thermal efficiency, specific fuel consumption, particle and $\mathrm{NO}$ emissions being observed. Hoang results [18] are influenced by good combustion properties of $\mathrm{H}_{2}$, such as higher combustion speed and higher LHV of Hydrogen, and a lower carbon content into the in-cylinder final mixture at Hydrogen use.

After an AVL software simulation, Rimkus [19] observes that the addition of hydrogen and oxygen, as $\mathrm{HHO}$, leads to a rapid ignition of mixture comparative to air-diesel fuel mixture. Hydrogen combustion leads to the decrease of the autoignition delay and of combustion intensity registered in the premixed phase [19]. Before TDC the combustion pressure and temperature increase at Hydrogen use, the heat release begins to be positive sooner per cycle as opposed to diesel fuel [19]. Acceleration of the combustion process in Hydrogen presence appears due to the higher combustion flame speed of $\mathrm{H}_{2}$. At medium engine loads, Hydrogen use in diesel engines leads to the increase of maximum pressure during combustion, but at low loads, this aspect is not so visible, according to Vard [20]. Hydrogen combustion efficiency starts to increase for $4 \%$ vol-\%vol. of Hydrogen [20]. Due to a higher LHV of Hydrogen compared to diesel fuel, even small quantities of $\mathrm{H}_{2}$ can assure the increase of engine efficiency.

In an experiment, Bika [21] uses an ethanol generator to produce Hydrogen which is further used to improve the combustion in a diesel engine. Hydrogen addition leads to an early start of combustion per cycle, with a higher rate, the maximum heat release rate being increased also [21]. The peak pressure and pressure increase rate present the same tendency in variation at Hydrogen use [21]. The tendency in the variation of combustion parameters is influenced by higher values of LHV and combustion speed of Hydrogen.

Lhuillier [22] uses mixtures of ammonia-hydrogen-air to fuel a PSA-EP6DT engine at the operating regime of $1500 \mathrm{rpm}$. Hydrogen affects the combustion duration, especially in the early stage of combustion, such as the initial stage [22]. The combustion is accelerated in the presence of hydrogen and its duration is reduced [22]. Hydrogen influences the ignition moment and the peak value of in-cylinder pressure that increases at hydrogen content increase [22]. The combustion duration is decreased, the final moment in combustion being achieved sooner per cycle as Hydrogen content increases to the maximum, with almost $20^{\circ} \mathrm{CA}$ at $\lambda=1-2$ [22]. Small quantities of Hydrogen can be used as combustion, promoter, the laminar burning velocity is influenced by Hydrogen during the main phase of combustion [22]. These aspects are in correlation with the wider flammability limits and higher combustion speed of the air-Hydrogen mixture.

Rouhollah [23] uses Hydrogen to fuel a Caterpillar 3401 heavy-duty diesel engine. The addition of Hydrogen leads to a sooner achievement of the ignition process, earlier combustion, and increases the rate of pressure increase per cycle [23]. The Hydrogen cyclic quantity is limited, at $60 \%$, in order to avoid knock combustion [23]. Sanli [24] evaluates the performance at different loads and compression ratios of the common-rail diesel engine fueled by methane and Hydrogen. The air-fuel mixture is auto ignited by a pilot of diesel fuel [24]. Comparative to classic operation, Hydrogen use ensures the increase of the maximum pressure and of the combustion noise. The heat release occurs sooner per cycle [24]. Saleh [25] studies the performance of a direct injection diesel engine fueled with different blends of diesel fuel, jojoba, and butanol, at speed of $1500 \mathrm{rpm}$. During the experiment, the DJ5B8 fuel, which contains $87 \%$ diesel fuel, $5 \%$ crude jojoba oil, and $8 \%$ butanol, blends with $0-20 \%$ vol. of Hydrogen peroxide [25]. Generally, the engine performance was improved, but the highest combustion performance was ensured for $5 \%$ hydrogen use [25]. These results are related to the higher values of LHV, flame speed, and wider flammability domain of Hydrogen, the increase of cycle efficiency being ensured even for small $\mathrm{H}_{2}$ quantities. Das [26] tests the performance of an $\mathrm{HHO}$ generator used to supply with Hydrogen gas an ICE. The use of oxy-hydrogen leads to the increase of engine idle speed with $25 \mathrm{rpm}$ and the maximum speed with $50 \mathrm{rpm}$, the temperature of exhaust gases being decreased by 1 Celsius degree [26].

Asai [27] uses a 4-cylinder diesel engine to test different fuels such as $\mathrm{H}_{2}, \mathrm{CO}, \mathrm{CH}_{4}$, as single fuels, or as blends. Compared to diesel fuel use, Hydrogen use causes the 
ignition delay starts to decrease, and the combustion duration is also reduced [27]. For gaseous fuel use at large engine loads, the combustion speed is increased, but a higher efficiency is achieved for Hydrogen fuel [27]. At medium and high engine loads, shortened combustion periods are registered to Hydrogen use comparative to diesel fuel or with the other gaseous fuel, $\mathrm{CO}$ and $\mathrm{CH}_{4}$ [27]. Even if the gaseous fuels are blended, the addition of Hydrogen leads to the decrease of combustion duration, the rate of combustion being increased. Finally, the Hydrogen quantity is limited in order to limit the in-cylinder maximum pressure [27]. A lower autoignition delay is ensured by the use of diesel fuel and Hydrogen [27], versus other gaseous fuels, $\mathrm{CO}$ and $\mathrm{CH}_{4}$. Compared to other tested fuels, the higher combustion speed of Hydrogen leads to the reduction of the combustion duration, the combustion being accelerated.

Shivaprasad [28] uses the Hydrogen addition in a single-cylinder engine, at idle speed regime. The increase of Hydrogen content leads to the increase of in-cylinder pressure and of the heat release rate, the increase rate of these parameters being also increased [28]. Shivaprasad [28] affirms that these aspects are related to the higher combustion speed of Hydrogen that leads to a shorter combustion period at its use.

Pochet [29] observes for a diesel engine that, if Hydrogen is used, compared to diesel fuel or to ammonia $\mathrm{NH}_{3}$, the combustion starts sooner per cycle and the combustion period is reduced, but the maximum heat release rate decreases from 4.5 (at $92 \%$ vol. $\mathrm{NH}_{3}$ ) to 1.6 (at pure $\mathrm{H}_{2}$ ).

Sathishkumar [30] shows that Hydrogen can influence the start-phase of combustion, the first peak in heat release rate being increased with $\mathrm{H}_{2}$ use. The combustion duration of the premixed phase is slightly reduced only at high engine load compared to low loads [30]. At low loads, the increase of Hydrogen addition leads to the decrease of the combustion main phase duration [30]. Compared to low loads, at average loads the combustion duration is not reduced at Hydrogen use, Sathishkumar [30] saying that these influences are probably connected to a complete propagation of the Hydrogen flame through the air-Hydrogen mixture, which indicates the participation of Hydrogen at the combustion process [30]. These combustion aspects are in correlation with higher diffusion and combustion speed, and a wide range of flammability of Hydrogen.

\subsection{Aim of Research}

The use of Hydrogen as an alternative fuel can be a viable solution to improve the ICE's performance, even for diesel engines. In order to fuel a diesel engine with Hydrogen, a conversion of a diesel engine to a spark-ignition engine (SIE) may be a solution. However, this technical solution requires major modification of the engine structure, including the mounting and optimization of new systems such as an ignition system, fueling system, etc., besides modifications in engine design (new compression ratio, different shape of the combustion chamber, etc.). Practically, the diesel engine is converted into an SIE and finally, the engine efficiency may be affected in this new configuration. For diesel engines, if the operating cycle remains unchanged, the engine efficiency can be improved, knowing that the diesel cycle operation is more efficient compared to the Otto cycle, the emission of $\mathrm{CO}_{2}$ being also lower compared to SIE's. The diesel cycle operation can be maintained if a diesel pilot ignites the air-Hydrogen mixture. In this way, a simpler fueling solution can be applied for new or in-use diesel engines, the fueling method being known as diesel-gas.

Different researchers use Hydrogen to fuel diesel engines and present the effect of Hydrogen on engine performance, in-cylinder maximum pressure, maximum pressure increase rate, autoignition delay, heat release, or level of pollutant emissions. In the present research, the authors use the diesel gas fueling method, which is relatively easy to adapt on diesel engines, to fuel a modern diesel engine with Hydrogen and diesel fuel in order to improve the engine efficiency. After experimental tests, the study is completed by the results of a thermodynamic model designed and developed by authors to evaluate the Hydrogen influence on in-cylinder processes. Thus, they are presented and analyzed aspect of vaporization, mixture forming, and combustion of diesel fuel droplets in an air-hydrogen 
mixture established in-cylinder for the dual-fueled diesel engine. The modeling design and studied parameters represent a novelty aspect of the research work in the field of Hydrogen use in diesel engines. Thus, with its novelty points, such as the Hydrogen influence on mixture forming, vaporization, combustion, and flame radius, which are further analyzed, this study completes the knowledge area in the field.

\section{Experimental Ant Theoretical Investigations Design}

At the experimental testbed, Figure 1, for the operating regime of $2000 \mathrm{rpm}$ and $55 \%$ engine load a number of 250 combustion cycles were measured.

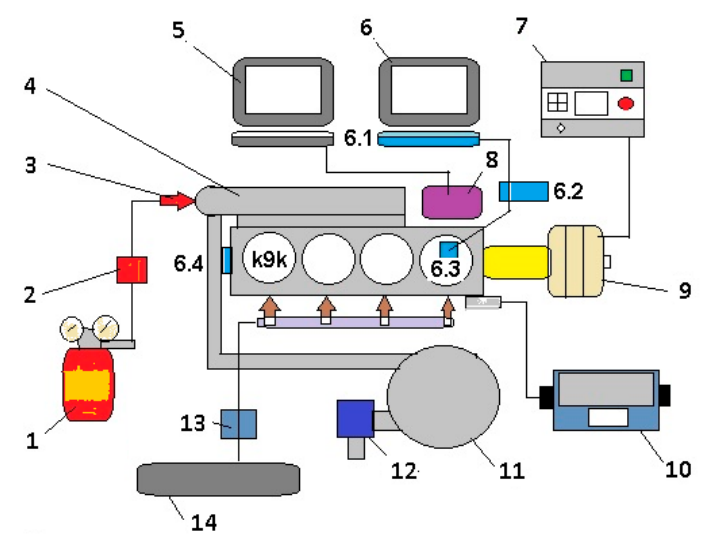

Figure 1. Hydrogen diesel engine experimental testbed has as main components: 1-Hydrogen tank, 2-Alicat Scientific MCR Hydrogen flowmeter, 3-Hydrogen injector, 4-K9K diesel engine, 5-Dastek Unichip computer, 6-AVL data acquisition system (AVL Indimodul Card C1 mounted in computer 6, 6.1-AVL Indimodul 621, 6.2-AVL 3067 charge amplifier, 6.3-AVL GU12P pressure transducer, 6.4-AVL 365CC angleencoder), 7-Horiba Schenck E 90 Dgital Controller, 8-ECU Unichip for injectors control, 9-Horiba Schenck E 90 Eddy-Current Dynamometer, 10-AVL DiCom 4000 gas analizer and opacimeter, 11-air reservoir, 12-Krohne air flowmeter 13-Optimass diesel fuel flowmeter, 14-diesel fuel tank.

The main characteristics of the experimental equipment are presented in Table 1.

Table 1. Main characteristics of testbed equipment.

\begin{tabular}{cccc}
\hline Measured Parameter & Measurement Device & Unit & Uncertainties \\
\hline Engine speed & Horiba Schenck E90 & $\mathrm{rpm}$ & $\pm 1 \mathrm{rpm}$ \\
Engine torque & Horiba Schenck E90 & $\mathrm{Nm}$ & $\pm 0.2 \%$ \\
Diesel flow rate & Optimass 3050 C & $\mathrm{kg} / \mathrm{h}$ & $\pm 0.1 \%$ \\
Hydrogen flow rate & Alicat Scientific MCR & $\mathrm{kg} / \mathrm{h}$ & $\pm 0.4 \%$ \\
Inlet air flow rate & Krohne H 250 & $\mathrm{m}^{3} / \mathrm{h}$ & $\pm 0.35 \%$ \\
In-cylinder pressure & AVL GU 12 P & $\mathrm{bar}$ & $\pm 0.05 \%$ \\
Crank angle degree & AVL 365 CC & ${ }^{\circ} \mathrm{CA}$ & $\pm 0.1 \%$ \\
& Thermocouple Cromel-Alumel TTC & ${ }^{\circ} \mathrm{C}$ & $\pm 1{ }^{\circ} \mathrm{C}$ \\
Temperatures & Thermoresistence P100 TTR & ${ }^{\circ} \mathrm{C}$ & $\pm 2{ }^{\circ} \mathrm{C}$ \\
& Shimaden SR93 indicators & ${ }^{\circ} \mathrm{C}$ & $\pm 0.3 \%$ \\
\hline
\end{tabular}

The diesel engine is dual-fueled with diesel fuel and Hydrogen. The classic fueling, only with diesel fuel, represents the reference regime, $x_{c}=0$. Further, Hydrogen inlet injection is used to partially substitute the diesel fuel, the maximum substitute ratio being $x c=20.97 \%$. During the substitution, the engine power is maintained at the same level, compared to classic fueling, due to an open type electronic control unit, Unichip Q, which allows the reduction of diesel fuel injection duration at the increase of Hydrogen cyclic rate via the increase of Hydrogen injector opening duration. Dastek-Unichip Software 
controls the injectors opening duration. Experimental data recorders inside cylinders are used for the analysis of fuel mixture formation and combustion. The authors concept and develop a phenomenological bi-zone model to study vaporization, mixture formation, and combustion of diesel fuel droplets at Hydrogen addition, a model which represents another novelty aspect of the research, a more detailed combustion analysis being achieved at the level of the fuel droplet. As input data, the experimental in-cylinder pressure diagrams, fuel, and air consumptions, fuel property characteristics (for diesel fuel and Hydrogen), exhaust gas temperature, etc., are used. In extenso, the model can be used at other operating regimes in order to establish the suitable Hydrogen cyclic quantity and to establish a prediction value of $x c$. At model conception, depicted in Figure 2, the following hypotheses are taken into consideration [31-34]:

- The fuel droplet and its flame envelope are concentric spheres of constant radius;

- Not taken into consideration are convection and radiation of the hot gases;

- The permanent vaporization regime is an isobar;

- The temperature of the droplet is similar to the diesel fuel boiling point;

- The thermal conductivity coefficient is not influenced by the temperature;

- Specific heats of the perfect gases (air, fuel vapors) are not influenced by the temperature;

- $\quad$ The droplet radius influences concentration and temperature.

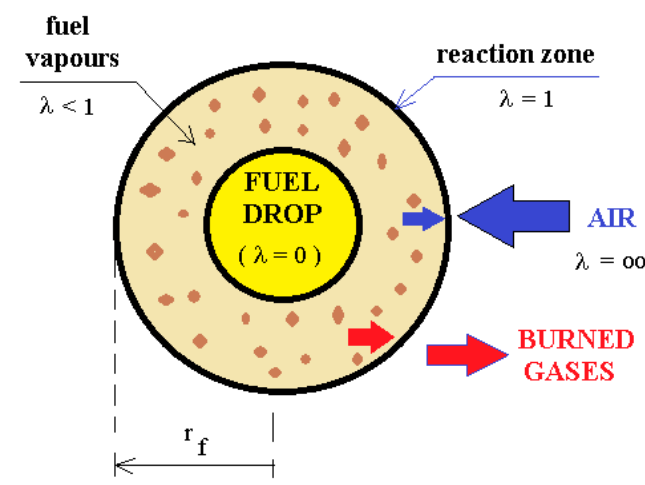

Figure 2. Spherical model for combustion of the fuel droplet [27].

The phenomenological model takes into consideration the global character of the diesel fuel injection, atomization, vaporization, and combustion of the diesel fuel droplets at Taylor and Kolmogorov scales $[31,32,34]$. The local reaction velocity is controlled only by the admixture velocity which is correlated by diffusion of fuel speed into the airspeed. If during the jet breakup period the jet speed remains unchanged, the jet breakup period is given by the formula for the time of atomization of the liquid jet $[31,32,34]$ :

$$
t_{a l j}=\frac{28.647 \cdot \rho_{f} \cdot d_{N}}{\sqrt{\Delta p_{i} \cdot \rho_{g}}}
$$

where $\Delta p_{i}$ in-cylinder and injection pressures differentiate, $\rho_{g}$-in-cylinder gases density, $\rho_{f}$-injected fuel density, bore of the nozzle $d_{N}=0.15 \mathrm{~mm}$, and 5 fuel jets.

In a pseudo-stationary regime, the time of vaporization for a diesel fuel droplet can be determined by the expression:

$$
t_{v}=\frac{\rho_{f} \cdot d_{p}^{2}}{8 \cdot \alpha_{g} \cdot \rho_{g} \cdot \ln (1+B)}
$$

The thermal diffusivity, $\alpha_{g}=\lambda_{g} / \rho_{g} c_{g}$, is defined by the specific heat $c_{g}(\mathrm{~J} / g)$, in-cylinder gases density $\rho_{g}\left(\mathrm{~kg} / \mathrm{m}^{3}\right)$ and thermal conductibility coefficient $\lambda_{g}(\mathrm{~W} / \mathrm{cm} \cdot \mathrm{deg})[31,32,34]$. Droplets resulted from diesel fuel spray atomization are defined by $10 \mu \mathrm{m}$ mean diameter, the vaporization velocity being influenced by the motion of the liquid-gas interface $[31,32,34]$. 
The new concept of vaporization of the liquid droplet and its combustion considers a sphere symmetrical system in which the diffusive combustion is developed in the flame cover that is created around the fuel droplet $[31,32,34]$. The liquid fuel droplet is fixed and has a spherical form, the vaporization being achieved in a steady-state regime. The liquid fuel and the surrounded fuel vapors have a constant temperature. The received heat, by convection thru a liquid droplet, diffuses in the droplet-vapor envelope assembly by a specific mass flow of substance [31,32,34]. The energy conservation equation is used to establish the total mass flow that fuels the droplet vaporization surface. The mass flow of the vapors that leave the vapor envelope, $w_{s}$, is controlled by convection and diffusion effects $[31,32,34]$. From the conditions established on the vaporization surface, the radius of the vapor envelope formed around the droplet defines the fuel droplet radius. The flow of evaporated fuel at droplet surface, $w_{s}$, is determined by:

$$
w_{s}=\frac{\alpha_{g} \cdot \rho_{g} \cdot \ln (1+B)}{r_{p}}
$$

using the number of mass transfer, $\mathrm{B}$, and the radius of the particle of diesel fuel, $r_{p}[31,32,34]$. The combustion speed is fundamentally related to the speed of mixture forming because the mixture-forming period is much bigger compared to the combustion period defined by speeds of chemical kinetic reactions $[31,32,34]$. In a fuel jet with uniform diameters of droplets, the relation that defines the mixture forming velocity is:

$$
\frac{d m_{f}}{d \alpha}=m_{i n j}^{0.333} \cdot m^{0.666} \cdot p_{\mathrm{O}_{2}}^{0.250}
$$

where $m_{i n j}$ is injected mass, $m$ is unformed mixture injected mass, $p_{\mathrm{O} 2}$ is the partial pressure of oxygen $[31,32,34]$.

Vaporized fuel flow on droplet surface, $w_{s}$, also defines the combustion speed at the liquid surface, when the boiling temperature is reached. Thus, the period of droplet combustion is determined by the following relation $[31,32,34]$ :

$$
t_{c}=\frac{\rho_{f} \cdot d_{p}^{2}}{8 \cdot \alpha_{g} \cdot \rho_{g} \cdot \ln (1+B)}
$$

After vaporization, a flame surrounds the fuel droplet with an infinitesimal thickness that separates the fuel from the oxidant. The flame placing is established by the radius of the flame, $r_{f}$, where oxidant and fuel vapors are at stoichiometric proportions [31,32,34]. The radius of the flame $r_{f}(\mathrm{~cm})$ is defined with the relation:

$$
r_{f}=\frac{w_{s} \cdot r_{p}^{2}}{\alpha_{g} \cdot \rho_{g} \cdot \ln \left(1+c \cdot y_{0}\right)}
$$

with $c$ stoichiometric mass ratio of fuel-oxygen and $y_{0}$ oxygen mass fraction in surrounding gases in the infinite medium [31,32,34].

\section{Results and Discussions}

The atomization of the diesel fuel jets and the vaporization of the diesel fuel droplets react to the gaseous environment established in-cylinder, the environment changed by Hydrogen presence. Thus, once with the increase of Hydrogen in-cylinder content the time needed for diesel fuel breakup starts to decrease compared to diesel fueling, Figure 3, at $x \mathcal{C}=20.97$, the decrease being around $12 \%$. 


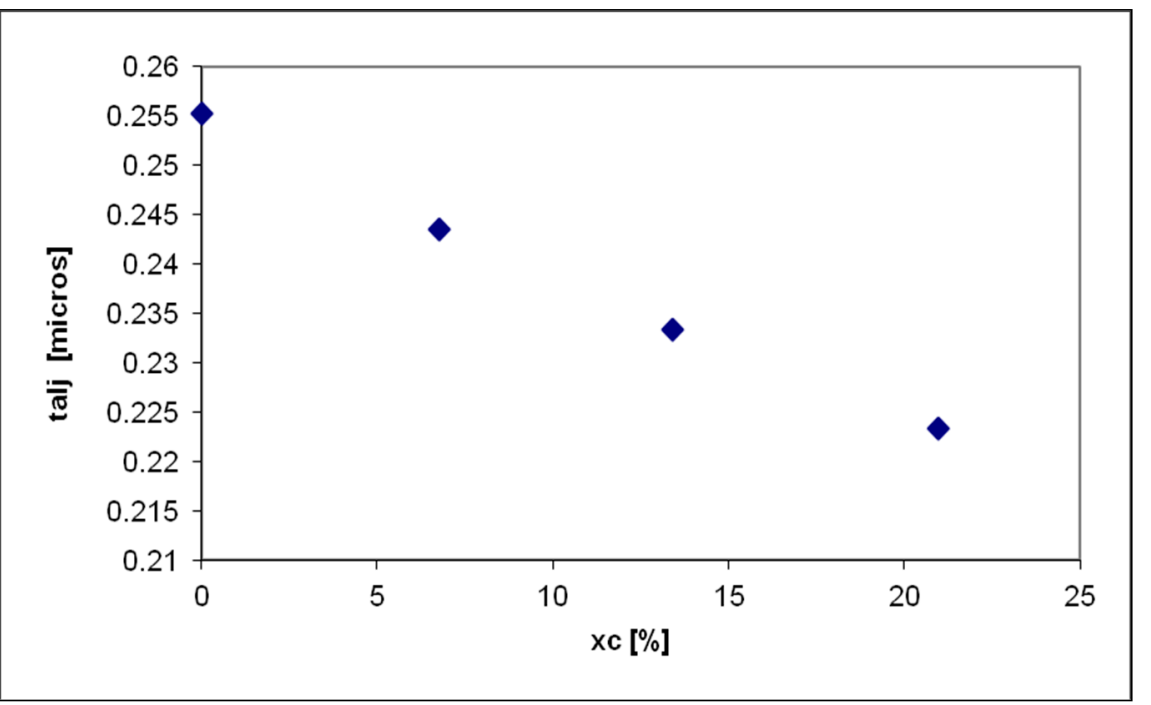

Figure 3. Time of fuel jet breakup versus substitute ratio at 55\% engine load and $2000 \mathrm{rpm}$ speed.

The decrease of the evaporation time of the diesel fuel droplets is presented in Figure 4 . The diesel fuel evaporated flow on droplet surfaces, Figure 5, represents the combustion speed, its variation being in correlation with the acceleration of the vaporization process, Figure 4. In the air-Hydrogen mixture combustion, assures the increase of the forming velocity of the air-Hydrogen-diesel droplets mixture, Figure 6. The time of diesel fuel droplets vaporization is reduced by $28 \%$ at hydrogen addition. The increase of mixture forming velocity is related to the decrease of diesel fuel breakup duration at $x c$ increase. After fuel atomization, the diesel droplets start to evaporate during a heating process and mix with the Hydrogen-air mixture driven into the fuel jet by a turbulence-diffusion process [31,32,34].

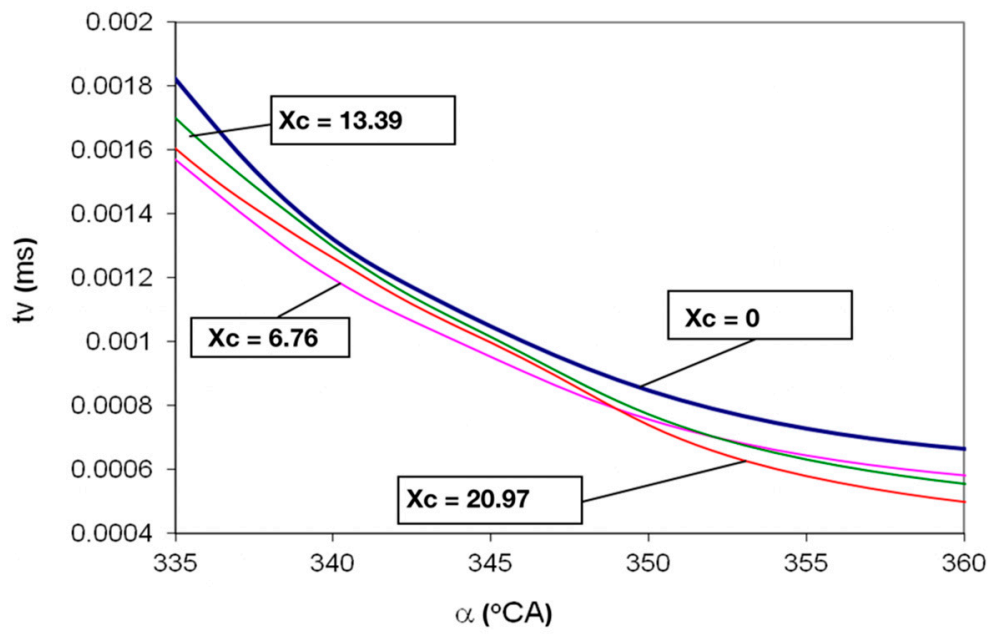

Figure 4. Time of vaporization of the liquid diesel fuel droplets at 55\% engine load and $2000 \mathrm{rpm}$ speed for different substitute ratios. 


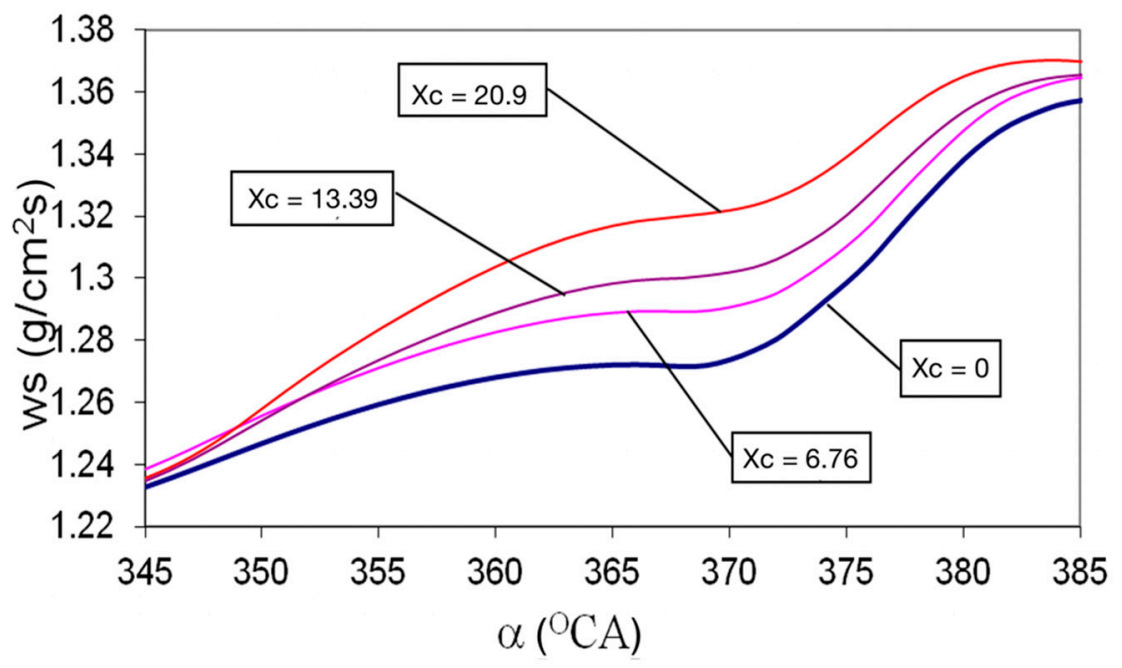

Figure 5. Mass flow of fuel vapors at droplets surface for 55\% engine load and $2000 \mathrm{rpm}$ speed for different substitute ratios.

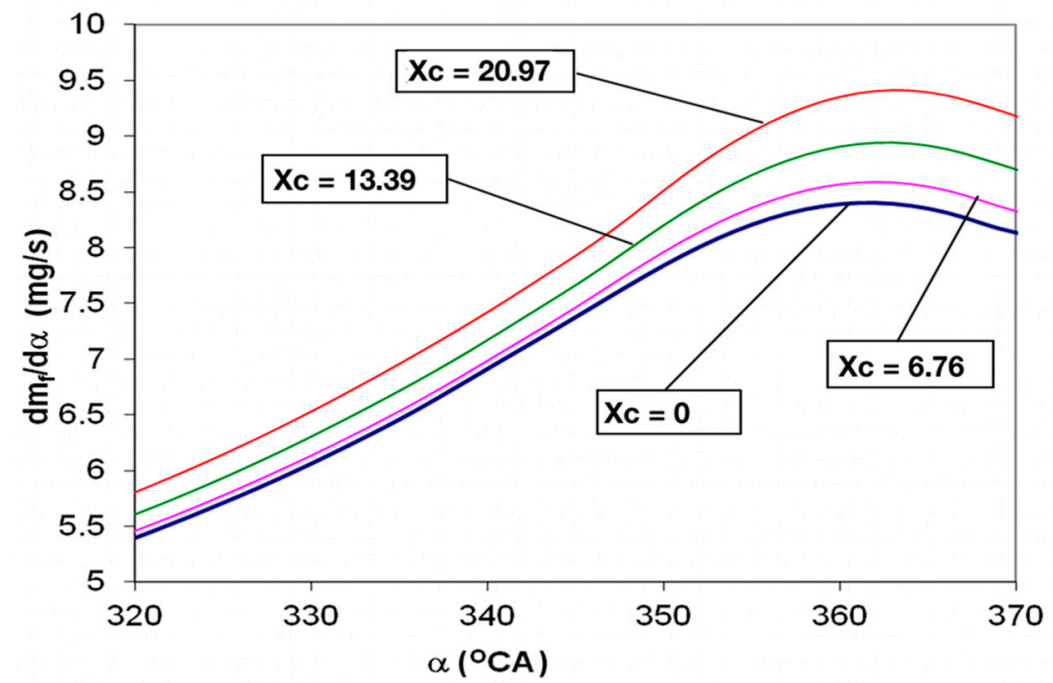

Figure 6. Mixture forming speed at 55\% engine load and $2000 \mathrm{rpm}$ speed for different substitute ratios.

As depicted in Figure 5, The higher heating value of Hydrogen assures the increase of heat release along the air-Hydrogen mixture combustion and intensifies vaporization and combustion of the fuel droplets situated close to air-Hydrogen lean mixtures which burn with high speeds. Compared to classic fueling, the evaporated flow on droplet surface increase by $3.9 \%$ at Hydrogen use and the maximum speed of droplets vaporization occurs earlier on cycle, with $5{ }^{\circ} \mathrm{CA}$ versus classic fueling, $x_{c}=0$. The autoignition of the diesel fuel droplets appears due to chemical transformations inside the zones defined by suitable mixture concentration and at the rise of hydrogen cyclic addition, the autoignition of diesel droplets decreases by $6 \%$. The increase of the evaporated mass flow assures the increase of burning speed and the decrease of droplet combustion time, Figure 7, in correlation with the tendency of autoignition decrease. Similar results, which show the reduction of autoignition delay at $\mathrm{H}_{2}$ use were defined from pressure and heat release rate diagram analysis, being presented in different research papers $[12,14,15,19-23,27,30]$. 


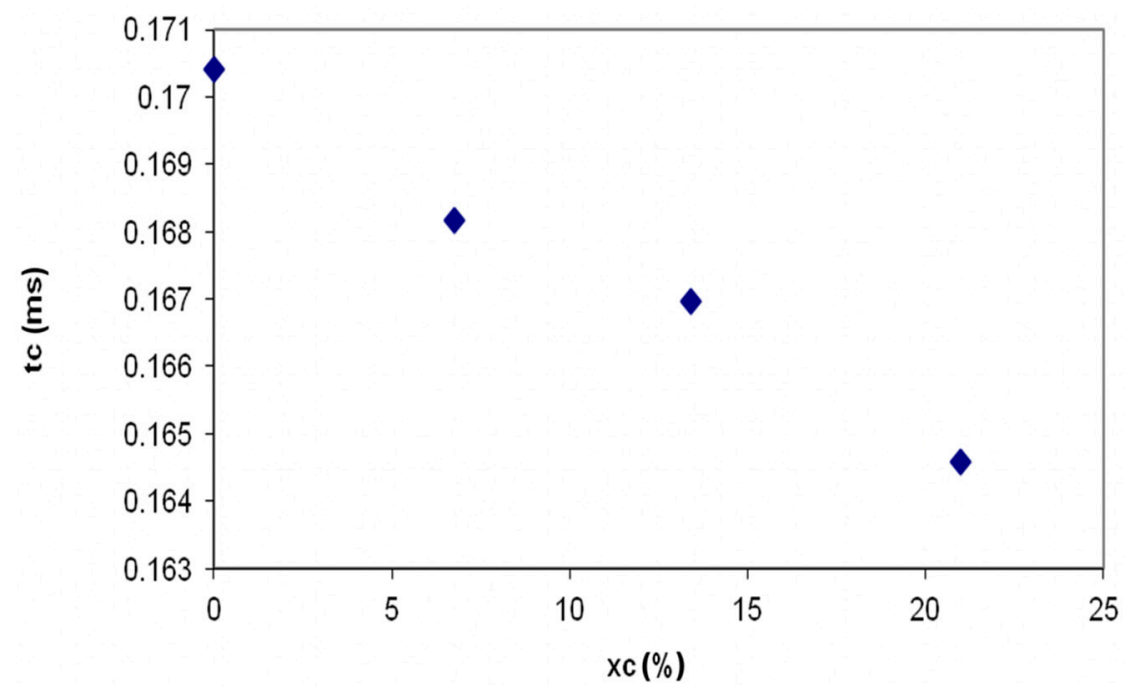

Figure 7. Combustion time of the fuel droplets versus substitute ratio at $55 \%$ engine load and 2000 rpm speed.

Due to the higher Hydrogen combustion rate, the combustion of the diesel droplet injected into an air-Hydrogen mixture is accelerated. The droplet's combustion time is reduced by $3.6 \%$ compared to classic fueling and the minimum combustion time of fuel droplets appears with $3{ }^{\circ} \mathrm{CA}$ sooner on cycle. The increase of the combustion speed assures the increase of the flame radius at Hydrogen-diesel fuel fueling, Figure 8, with $3.8 \%$ at the maximum $x c$. Different research papers present pressure and heat release diagrams analysis, which show the reduction of combustion duration at Hydrogen use [14,15,19-23,27-29], which is related to the decreasing tendency in combustion time at $\mathrm{H}_{2}$ use, Figure 7.

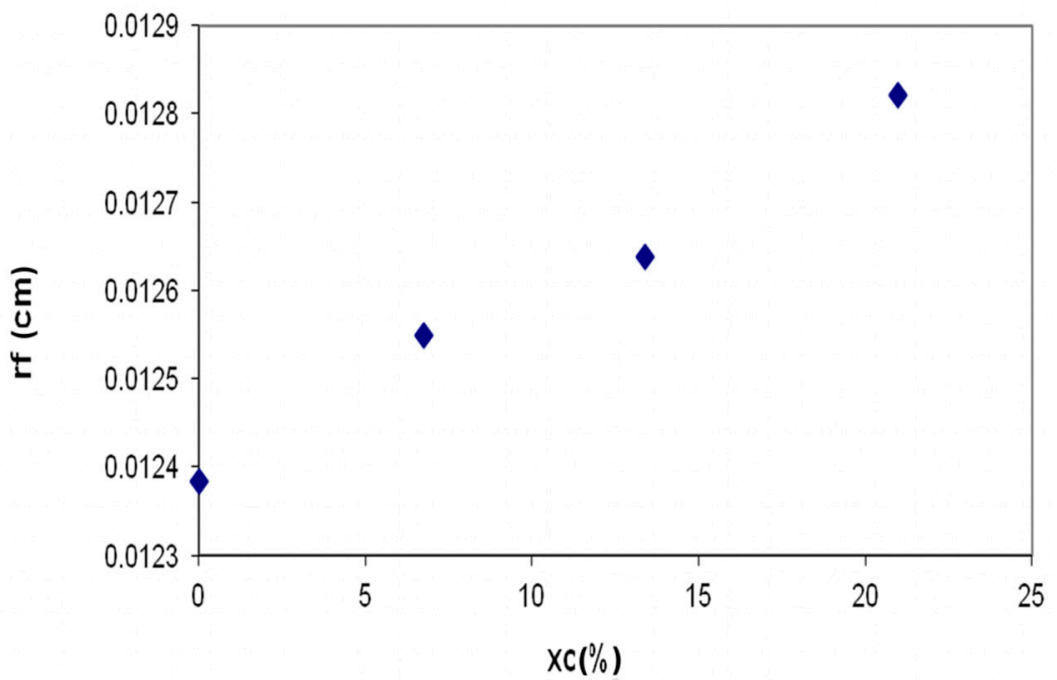

Figure 8. Radius of the flame around the fuel droplets versus substitute ratio at $55 \%$ engine load and 2000 rpm speed.

Hydrogen combustion leads to the acceleration of the flame developing, the maximum radius of the flame developed around the fuel droplet being registered with $3{ }^{\circ} \mathrm{CA}$ sooner on the combustion cycle compared to $x c=0$. Thus, in the presence of air-Hydrogen mixtures, the flame development around the diesel fuel droplet is accelerated and the flames become larger at the increase of $x c$, the duration of the combustion process being shortened. The increase of the combustion intensity at Hydrogen use, reflected in the decrease of fuel droplets combustion duration, Figure 7, and increase of flame radius, Figure 8, is in correlation with the increase of maximum pressure and of maximum pressure increase rate 
at this operating regime with $13 \%$ and $29 \%$, respectively [1]. Similar aspects are shown in other research papers [12-18,21-23,27-30].

In order to validate the model, according to combustion calculus, the motor fluid volume variation speed, the variation of the mechanical work speed produced by the motor fluid, and the temperature differential equation are calculated and used to determine the variation of theoretical pressure, in concordance with the equation of state. Thus, in-cylinder pressure theoretical variations are obtained with the thermodynamic model for classic fueling, and for dual fueling, the calculation error not exceeding $1 \%$. At the same operating regime, for diesel fueling, $x_{c}=0$, and for maximum $x_{c}$ value, $x_{c}=20.97$, the theoretical pressure diagrams are compared with experimental averaged pressure diagrams and presented in Figure 9.
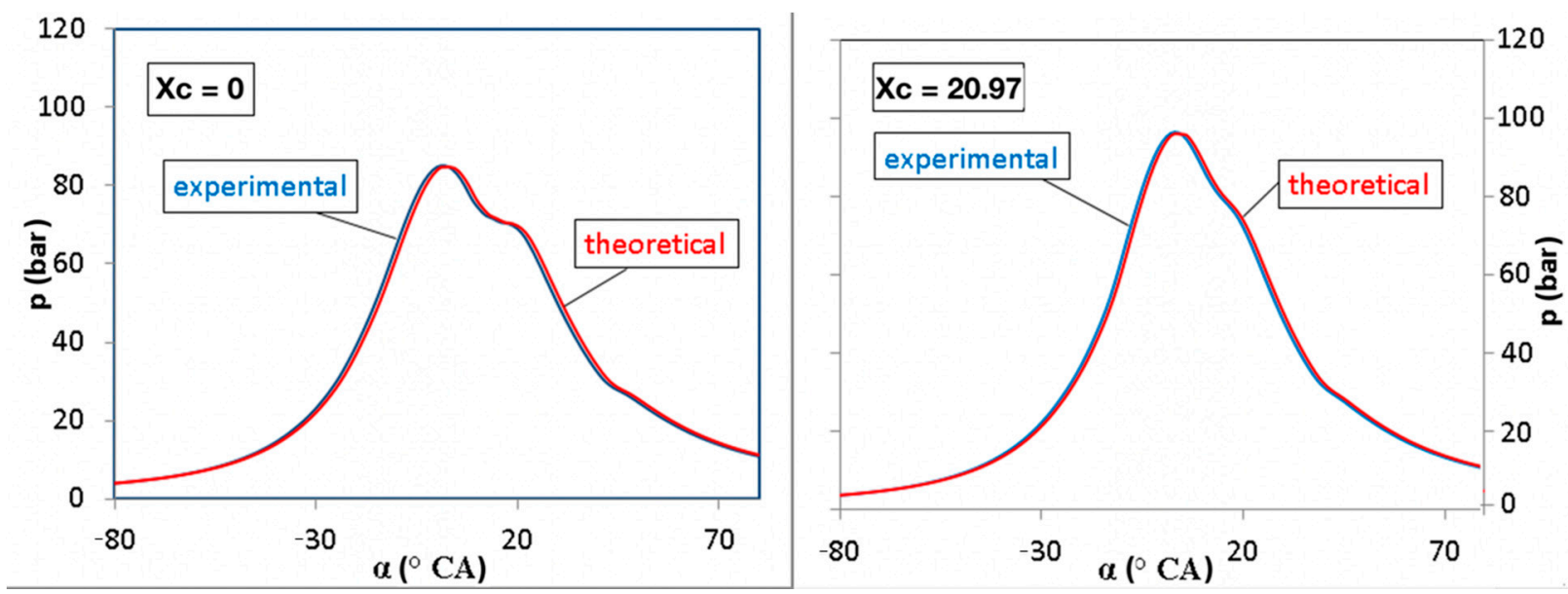

Figure 9. Theoretical and experimental diagrams for classic fueling and Hydrogen-diesel fuel fueling at maximum xc, at $55 \%$ engine load and $2000 \mathrm{rpm}$ speed.

\section{Conclusions}

Novelty aspects of vaporization, mixture forming and combustion of diesel fuel droplets at injection into a mixture of air-Hydrogen can complete the field of knowledge of Hydrogen use in diesel engines. The modeling analysis results leads to the following main conclusions:

- Diesel fuel jets atomization and diesel fuel droplets vaporization of the diesel fuel are influenced by the presence of Hydrogen in the in-cylinder gaseous mixture. When Hydrogen content is increased, the duration of diesel fuel breakup starts to decrease with $12 \%$ at maximum $x c$ versus classic fueling;

- The decrease of the evaporation time of the diesel fuel droplets by up to $28 \%$, in the air-Hydrogen mixture combustion, ensures the increase of formation speed of the mixture between air-Hydrogen and diesel fuel droplets;

- The increase of mixture forming speed is related to the decrease of diesel fuel breakup duration at $x c$ increase;

- The increase of combustion speed of diesel fuel droplets is in correlation with the acceleration of the vaporization process;

- Higher hydrogen heating value ensures the increase of heat released during combustion of the air-Hydrogen mixture and intensifies vaporization and combustion of the diesel fuel droplets which are situated in the vicinity of air-Hydrogen lean mixtures that burn at high speeds;

- The evaporated flow on the droplet surface increases by $3.9 \%$ and the maximum speed of droplets vaporization occurs sooner on cycle, with $5{ }^{\circ} \mathrm{CA}$ when comparing Hydrogen use versus classic fueling, $x c=0$; 
- Diesel fuel droplets autoignition decreases by $6 \%$ when Hydrogen is added into the inlet air;

- The increase of the evaporated mass flow ensures the increase of burning speed and the decrease of droplet combustion time, in correlation with the tendency of autoignition decrease;

- Due to higher Hydrogen combustion rate, the combustion of the diesel droplet injected into an air-Hydrogen mixture is accelerated, the droplets combustion time being reduced by $3.6 \%$ versus classic fueling; the minimum combustion time of fuel droplets appears with $3{ }^{\circ} \mathrm{CA}$ sooner on cycle;

- The flame radius increases by $3.8 \%$ at maximum $\mathrm{xc}$, in correlation with the increase of the combustion speed; Hydrogen combustion leads to the acceleration of the flame developing, the maximum radius of the flame developed around the fuel droplet being registered with $3{ }^{\circ} \mathrm{CA}$ sooner on combustion cycle comparative to $x c=0$. In the presence of air-Hydrogen mixtures, the development of the flame around diesel fuel droplets is accelerated and the flames become larger at the increase of $x c$, the duration of the combustion process being shortened.

Author Contributions: Conceptualization, A.C., C.P., N.N., C.N. and G.L.; methodology, A.C., C.P., N.N. and C.N.; software A.C., C.P., N.N. and C.N.; validation, A.C., C.P. and N.N.; formal analysis, A.C., C.P., N.N., C.N. and G.L.; investigation, A.C., C.P., N.N., C.N. and G.L.; resources, A.C., C.P., N.N., C.N. and G.L.; data curation, A.C., C.P., N.N. and C.N.; writing-original draft preparation, A.C., C.P., N.N., C.N. and G.L.; writing-review and editing, A.C., C.P., N.N., C.N. and G.L.; visualization, A.C., C.P., N.N., C.N. and G.L.; supervision, A.C., C.P., N.N. and G.L.; project administration, A.C., C.P., N.N. and G.L.; funding acquisition, A.C., C.P., N.N. and G.L. All authors have read and agreed to the published version of the manuscript.

Funding: This work was supported by a grant of the Romanian Ministery of Research and Innovation, CCCDI-UEFISCDI, project number PN-III-P1-1.2-PCCDI-2017-0404/31PCCDI/2018, within PNCDI III.

Data Availability Statement: The data presented in this study are available on request from the corresponding author.

Acknowledgments: The authors address special thanks to AVL GmbH Graz Austria for providing the necessary equipment. The work has been funded by the Sectoral Operational Programme Human Resources Development of the Ministry of European Funds through the Financial Agreement POSDRU/159/1.5/S/134398.

Conflicts of Interest: The authors declare no conflict of interest.

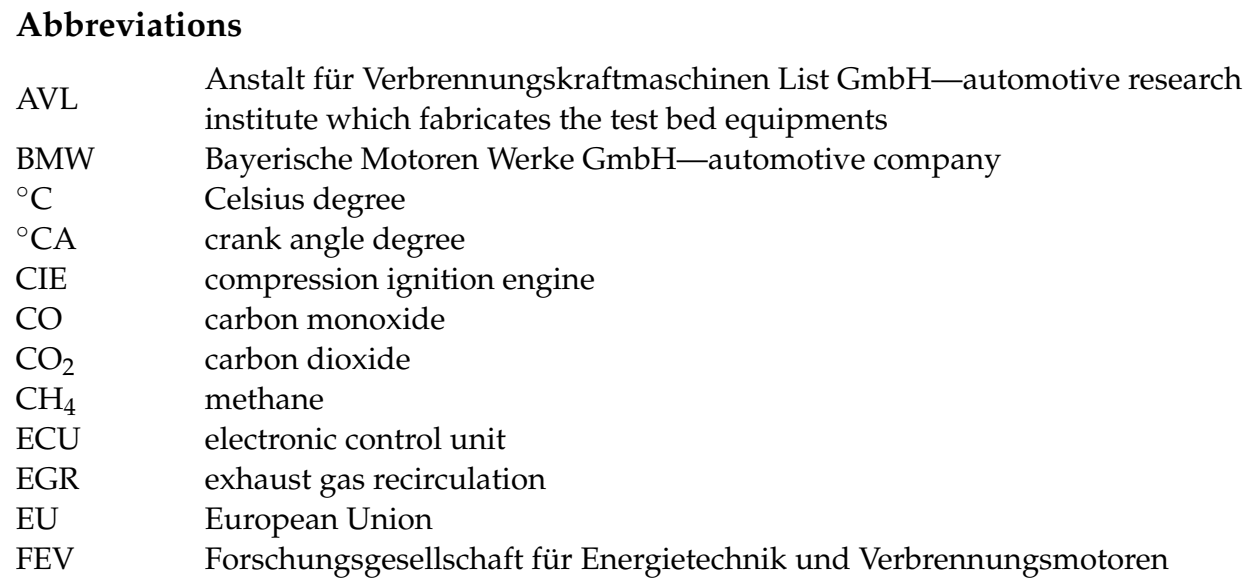




$\begin{array}{ll}\mathrm{GHG} & \begin{array}{l}\text { greenhouse gas } \\ \text { hydrogen } \\ \mathrm{H}_{2}\end{array} \\ \mathrm{HCCI} & \begin{array}{l}\text { homogeneous charge compression ignition } \\ \text { oxyhydrogen gas with a 2:1 ratio of hydrogen and oxygen }\end{array} \\ \mathrm{HHO} & \text { internal combustion engine } \\ \mathrm{ICE} & \text { lower heating value } \\ \mathrm{LHV} & \text { ammonia } \\ \mathrm{NH}_{3} & \text { research and development } \\ \mathrm{R} \& \mathrm{r} & \text { revolutions per minute } \\ \mathrm{rpm} & \text { top dead centre } \\ \mathrm{TDC} & \text { diesel fuel substitute ratio with Hydrogen, \% energetic } \\ x C & \text { crankshaft angular position } \\ \alpha & \text { air fuel ratio }\end{array}$

\section{References}

1. Vision 2050. A Pathway for the Evolution of the Refining Industry and Liquid Fuels. Fuels Europe; European Union Communication: Brussels, Belgium, 2018. Available online: https://www.fuelseurope.eu/wp-content/uploads/2018/04/DEF_EN_FE_Vision205 0_digital.pdf (accessed on 7 December 2020).

2. DG MOVE-Expert Group Future Transport Fuels. State of Art on Alternative Fuels Transport Systems in the European Union; Final Report; European Union Communication: Brussels, Belgium, 2015.

3. Bauen, A.; Gomez, I.; OudeNijeweme, D.; Paraschiv, M. European Commission, Directorate-General Research and Innovation, Smart, Green and Integrated Transport; Alternative Fuels; Expert Group Report; Studies and Reports; European Union Comunication: Brussels, Belgium, 2017.

4. Popa, M.G.; Pana, C.; Negurescu, N. Diesel Engines. Processes; Matrixrom: Bucharest, Romania, 2003; pp. 1-706.

5. Cernat, A.; Pana, C.; Negurescu, N.; Lazaroiu, G.; Nutu, C.; Fuiorescu, D. Hydrogen-As alternative fuel for diesel engines used in Transportation. Sustainability 2020, 12, 9321. [CrossRef]

6. $\quad$ Lazaroiu, G.; Pană, C.; Mihaescu, L.; Cernat, A.; Negurescu, N.; Mocanu, R.; Negreanu, G. Solutions for energy recovery of animal waste from leather industry. Energy Convers. Manag. 2017, 149, 1085-1095. [CrossRef]

7. Cernat, A.; Pana, C.; Negurescu, N.; Fuiorescu, D.; Nutu, C.; Mirica, I. Experimental Aspects of Hydrogen Use at Diesel Engine by Diesel Gas Method. Therm. Sci. 2018, 22, 1191-1200. [CrossRef]

8. Hydrogen View. Available online: https://www.H2-view.com (accessed on 13 November 2020).

9. Koch, D.; Ebert, T.; Sousa, A. Engine Adaptation from Diesel to $\mathrm{H}_{2}$ HP-EGR Lean Combustion Concept. MTZ Worldw. 2020, 81, 31-37. [CrossRef]

10. Curry, P. Hydrogen: The Best Alternative to Internal Combustion? Auto Vista Group, 2019. Available online: https:// autovistagroup.com/news-and-insights/hydrogen-best-alternative-internal-combustion (accessed on 13 November 2020).

11. FEV Is Driving Forward Hydrogen Internal Combustion Engine Development. Available online: https://www.fev.com/uploads/ media/PR_Hydrogen-Engine.pdf (accessed on 5 September 2020).

12. Korn, T. The Hydrogen Engine is on its Way. MTZ Worldw. 2020, 81, 74. [CrossRef]

13. Szwaja, S.; Grab-Rogalinski, K. Hydrogen combustion in a compression ignition diesel engine. Int. J. Hydrog. Energy 2009, 34, 4413-4421. [CrossRef]

14. Karagöz, Y.; Sandalici, T.; Yuksek, L.; Wongwisess, S. Effect of hydrogen-diesel dual-fuel usage on performance, emissions and diesel combustion in diesel engines. Adv. Mech. Eng. 2016, 8. [CrossRef]

15. Tutak, W.; Grab-Rogalinski, K.; Jamrozik, A. Combustion and Emission Characteristics of a Biodiesel-Hydrogen Dual-Fuel Engine. Appl. Sci. 2020, 10, 1082. [CrossRef]

16. Qin, Z.; Yang, Z.; Jia, C.; Duan, J.; Wang, L. Experimental study on combustion characteristics of diesel-hydrogen dual-fuel engine. J. Therm. Anal. Calorim. 2020, 142, 1483-1491. [CrossRef]

17. Temizer, I.; Cihan, O. Analysis of different combustion chamber geometries using hydrogen/diesel fuel in a diesel engine. Energy Sources Part A Recover. Utilization Environ. Effects 2020, 1-18. [CrossRef]

18. Hoang, A.T.; Pham, V.V. A study on a solution to reduce emissions by using hydrogen as an alternative fuel for a diesel engine integrated exhaust gas recirculation. AIP Conf. Proc. 2020, 2235, 1. [CrossRef]

19. Rimkus, A.; Pukalskas, S.; Juknelevičius, R.; Jonas Matijošius, J.; Kriaučiūnas, D. Evaluating Combustion, Performance and Emission Characteristics of CI Engine Operating on Diesel Fuel Enriched with HHO Gas. J. Kones 2019, 25, 2. [CrossRef]

20. Vard, A.A. A Study on the Effects of Combined Diesel-Hydrogen Combustion on Diesel Engines Using Experimental and Simulation Techniques. Ph.D. Thesis, Brunel University School of Engineering and Design, London, UK, September 2018.

21. Bika, A.S.; Franklin, L.; Kittelson, D.B. Hydrogen Assisted Combustion of Ethanol in Diesel Engines. University of Minnesota. 2020. Available online: http:/ / dept.me.umn.edu/centers/cdr/reports/agexpoposter.pdf (accessed on 26 August 2020).

22. Lhuillier, C.; Brequigny, P.; Contino, F.; Mounaim-Rousselle, C. Experimental study on ammonia/hydrogen/air combustion in spark ignition engine conditions. Fuel 2020, 269, 117448. [CrossRef] 
23. Rouhollah, A.; Mohammad, S.H. Numerical investigation on adding/substituting hydrogen in the CDC and RCCI combustion in a heavy duty engine. Appl. Energy 2018, 213, 450-468. [CrossRef]

24. Şanlı, A.; Yılmaz, I.T.; Gümüş, M. Experimental Evaluation of Performance and Combustion Characteristics in a HydrogenMethane Port Fueled Diesel Engine at Different Compression Ratios. Energy Fuels 2020, 34, 2272-2283. [CrossRef]

25. Saleh, H.E. Performance and emissions characteristics of direct injection diesel engine fueled by diesel-jojoba oil-butanol blends with hydrogen peroxide. Fuel 2020, 285, 119048. [CrossRef]

26. Das, B.; Pai, A.; Kini, C.R. Oxy-hydrogen hybrid diesel engine. J. Eng. Appl. Sci. 2020, 15, 1063-1068.

27. Asai, G. A Study of Gas-Diesel Dual Fuel Combustion for Higher Thermal Efficiency and Lower Emissions. Yanmar Tech. Rev. Res. Dev. Manag. Div. 2019. Available online: https://www.yanmar.com/nz/about/technology/technical_review/2019/1001_6.html (accessed on 3 September 2020).

28. Shivaprasad, K.V.; Chitragar, P.R.; Kumar, G.N. Effect of Hydrogen Addition on Combustion and Emissions Performance of a High Speed Spark Ignited Engine at Idle Condition. Therm. Sci. 2018, 22, 1405-1413. [CrossRef]

29. Pochet, M.; Jeanmart, H.; Contino, F. A 22:1 Compression Ratio Ammonia-Hydrogen HCCI Engine: Combustion, Load, and Emission Performances. Fundamental Characterization and performance of alterative fuels. Front. Mech. Eng. 2020, 6, 43. [CrossRef]

30. Sathishkumar, S.; Mohamed Ibrahim, M. Effect of Hydrogen Energy Share on a Hydrogen Diesel Dual Fuel Mode using a Common Rail Direct Injection System. Int. J. Eng. Adv. Technol. 2019, 9, 1-7.

31. Merker, G.; Schwarz, C.; Teichmann, R. Internal Combustion Engines Fundamentals: Running, Simulation, Measuring; Springer: Berlin, Germany, 2011. [CrossRef]

32. Felis-Carrasco, F. Atomization and Dispersion of Liquid Jets: Numerical and Experimental Approaches. Ph.D. Thesis, Ecole Centrale Marseille, Marseille, France, March 2017. Available online: https://tel.archives-ouvertes.fr/tel-01558141 (accessed on 26 December 2020).

33. Pimsner, V.; Vasilescu, C.; Radulescu, G. Energetics of Internal Combustion Turbo-Engines; Academy of RPR: Bucharest, Romania, 1964.

34. Apostolescu, N.; Chiriac, R. Combustion Process in Internal Combustion Engines, Fuel Economy and Emissions Control; Tehnica: Bucharest, Romania, 1998. 